\title{
Effect of the ionic product of bioglass 60s on osteoblastic activity in canines
}

\author{
Endrigo G L Alves ${ }^{1,2}$, Rogéria Serakides ${ }^{2}$, Isabel R. Rosado ${ }^{2}$, Marivalda M. Pereira ${ }^{3}$, Natália M. Ocarino², \\ Humberto P. Oliveira ${ }^{2}$, Alfredo M. Góes ${ }^{4}$ and Cleuza M F Rezende ${ }^{2^{*}}$
}

\begin{abstract}
Background: The objective of the present study was to evaluate the effect of the ionic product (IP) of BG60S on osteoblastic activity. The following media groups were created: DMEM, which is formed by osteoblasts in basal medium; IP DMEM, which is formed by osteoblasts in IP with basal medium; OST, which is formed by osteoblasts in osteogenic medium; and IP OST, which is formed by osteoblasts in IP with osteogenic medium. The osteoblasts were cultivated in an incubator at $37{ }^{\circ} \mathrm{C}$ and $5 \% \mathrm{CO}_{2}$ for 7,14 and 21 days. After each period, the alkaline phosphatase (AP) activity, mineralised area per field and expression of osterix (OSX), bone sialoprotein (BSP), osteonectin (ON) and osteocalcin (OC) were evaluated by reverse transcription (RT)-PCR.

Results: The IP significantly increased the AP activity in the IP DMEM group at 7 and 14 days and reduced the AP activity in the IP OST group at 14 and 21 days relative to their respective controls (DMEM and OST). The groups that received the IP displayed a significant increase in the percentage of mineralised area per field and more advance maturation of the extracellular matrix relative to those that did not receive IP. The IP significantly increased the expression of OSX, BSP and ON in osteoblast cultures maintained in IP DMEM compared with the control (DMEM) for the majority of studied periods. In osteogenic medium, IP also significantly increased OSX, BSP, ON and OC expression compared with the control (OST) for the majority of studied periods.
\end{abstract}

Conclusions: The IP of BG60S alters the gene expression of canine osteoblasts, favouring the synthesis and mineralisation of the extracellular matrix.

Keywords: Orthopaedics, Biomaterials, Bone substitute, Osteoblasts

\section{Background}

Bioglass 60S (BG60S) has a molar composition of $4 \%$ $\mathrm{P}_{2} \mathrm{O}_{5}, 36 \% \mathrm{CaO}$ and $60 \% \mathrm{SiO}_{2}$, is a biomaterial with favourable characteristics for bone regeneration [1] and displays beneficial effects on the repair of bone defects in dog jaws [2]. But nothing is known about the effect of this biomaterial on the activity of dog osteoblasts, especially as regards the production of extracellular matrix and osteogenic differentiation. Generally speaking, when the bioglass is implanted on the bone tissue, it provides a framework for migration and colonization by osteoblasts, and apart from this, it reacts with the interstitial

\footnotetext{
* Correspondence: cleuzaufmg@gmail.com

${ }^{2}$ Center for Stem Cells and Animal Cell Therapy (Núcleo de Células Tronco e Terapia Celular Animal - NCT-TCA), Department of Medicine and Surgery, Veterinary School of the Federal University of Minas Gerais (Universidade Federal de Minas Gerais - UFMG), Belo Horizonte, Brazil

Full list of author information is available at the end of the article
}

fluids, releasing ions, mainly calcium and silicon [3], which are, probably, primarily responsible for the biological effect.. These ions may favour osteogenic proliferation $[4,5]$ and differentiation in vitro $[5,6]$. However, the ideal chemical composition of bioglass that releases the ideal combination and concentration of ions to maximise the bone regeneration process upon implantation is not well understood. In an in vitro study with rat osteoblasts, BG60S exhibited satisfactory $\mathrm{Ca}$ and $\mathrm{Si}$ release rates, which favours cellular proliferation [3]. However, the effects of this biomaterial on canine osteoblast activity are unknown. Osteoblasts perform a crucial function in the bone regeneration process by producing and secreting the extracellular bone matrix. The objective of the present study was to investigate the hypothesis that the ionic product $(I P)$ of BG60S will increase the synthesis and mineralisation of the extracellular matrix 
by evaluating the effect of the IP on canine osteoblastic activity.

\section{Results}

Concentrations of $\mathrm{Si}$ and $\mathrm{Ca}$ ions in cell culture media When added to cell culture media, BG60S was partially dissolved, causing a significant increase in the concentration of $\mathrm{Si}$ and $\mathrm{Ca}$ ions. The concentration of $\mathrm{Si}$ ions was $40.91 \mathrm{mg} / \mathrm{L}$ in IP DMEM medium (which is formed by osteoblasts in $I P$ with basal medium), $41.28 \mathrm{mg} / \mathrm{L}$ in IP OST medium (which is formed by osteoblasts in IP with osteogenic medium) and lower than $1 \mathrm{mg} / \mathrm{L}$ in the media with no contact with BG60S (DMEM and OST, which are formed by osteoblasts in basal medium and osteoblasts in osteogenic medium, respectively). The concentration of $\mathrm{Ca}$ ions was $96.5 \mathrm{mg} / \mathrm{L}$ in $D M E M$ medium, $87.5 \mathrm{mg} / \mathrm{L}$ in $O S T$ medium, $169 \mathrm{mg} / \mathrm{L}$ in $I P$ $D M E M$ medium and $156.5 \mathrm{mg} / \mathrm{L}$ in IP OST medium. Hence, BG60S increased the concentration of $\mathrm{Ca}$ ions by 75 and $79 \%$ in basal and osteogenic media, respectively.

\section{Alkaline phosphatase activity}

The osteoblast cultures maintained in IP DMEM exhibited higher alkaline phosphatase (AP) activity than those maintained in DMEM at 7 and 14 days and lower AP at 21 days (Fig. 1). The IP OST group displayed lower AP activity than group OST at 14 and 21 days, and no difference was observed at 7 days (Fig. 1). Higher AP activity was observed in the OST group relative to the DMEM group at all times studied. The cultures maintained in $I P$ $D M E M$ displayed higher activity than those in IP OST at 7 and 14 days, and no difference was observed at 21 days (Fig. 1).

\section{Evaluation of the mineralised matrix synthesis}

The osteoblast cultures maintained in IP DMEM displayed a higher mineralised area per field than that of cultures maintained in DMEM at 14 and 21 days and lower mineralised area per field at 7 days (Figs. 2 and 3). The IP OST group displayed a higher mineralised area by field than the OST group at 7,14 and 21 days of culture (Figs. 2 and 3). The IP DMEM and IP OST groups exhibited a higher mineralisation of the matrix than did the DMEM and OST groups, respectively (Fig. 3). The $D M E M$ group displayed a higher mineralised area by field than the OST group for all times studied (Figs. 2 and 3). The cultures maintained in $I P$ $D M E M$ displayed a larger mineralised area per field than that of cultures maintained in IP OST at 14 and 21 days and a smaller mineralised area per field at 7 days; however, the IP OST group exhibited a higher mineralisation of the extracellular matrix than did the IP DMEM group (Figs. 2 and 3).

\section{Quantification of gene transcriptions for OSX, BSP, ON and $\mathrm{OC}$}

The osteoblast cultures maintained in IP DMEM exhibited higher osterix (OSX) expression than those maintained in $D M E M$ at 7 and 21 days, and no difference was observed at 14 days (Fig. 4). Group IP OST displayed greater OSX expression than group OST, at 7, 14, and 21 days of culture (Fig. 4). At 7 and 21 days of culture, higher OSX expression was observed in group OST relative to group $D M E M$, and at 14 days, no difference was observed (Fig. 4). The cultures maintained in IP OST exhibited greater OSX expression than those maintained in IP DMEM at 7, 14, and 21 days of culture (Fig. 4).

The osteoblast cultures maintained in IP DMEM displayed greater bone sialoprotein (BSP) expression than those maintained in DMEM at 7 and 21 days, and no difference was observed at 14 days (Fig. 5). The IP OST group displayed higher BSP expression than did the OST group at 7, 14, and 21 days of culture (Fig. 5). Lower BSP expression was observed in the OST group compared with the DMEM group at 7, 14 and 21 days (Fig. 5). The cultures maintained in IP OST exhibited greater BSP expression than those maintained in IP $D M E M$ at 14 and 21 days of culture and lower BSP expression at 7 days (Fig. 5).

The osteoblast cultures maintained in IP DMEM displayed higher osteonectin (ON) expression than those
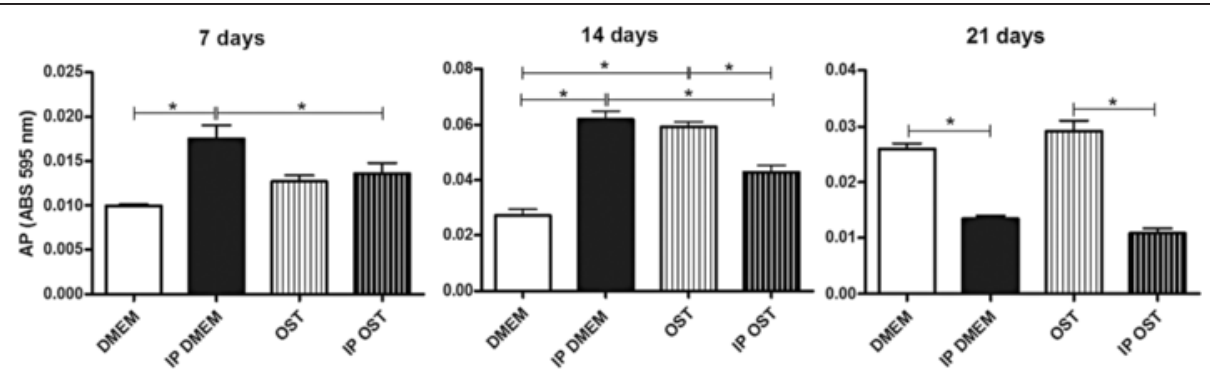

Fig. 1 Mean and standard deviation of the alkaline phosphatase activity in canine osteoblast cultures maintained in basal medium (DMEM), ionic product in basal medium (IP DMEM), osteogenic medium (OST) and ionic product in osteogenic medium (IP OST) at 7,14 and 21 days. ${ }^{*}(P<0.05)$ 


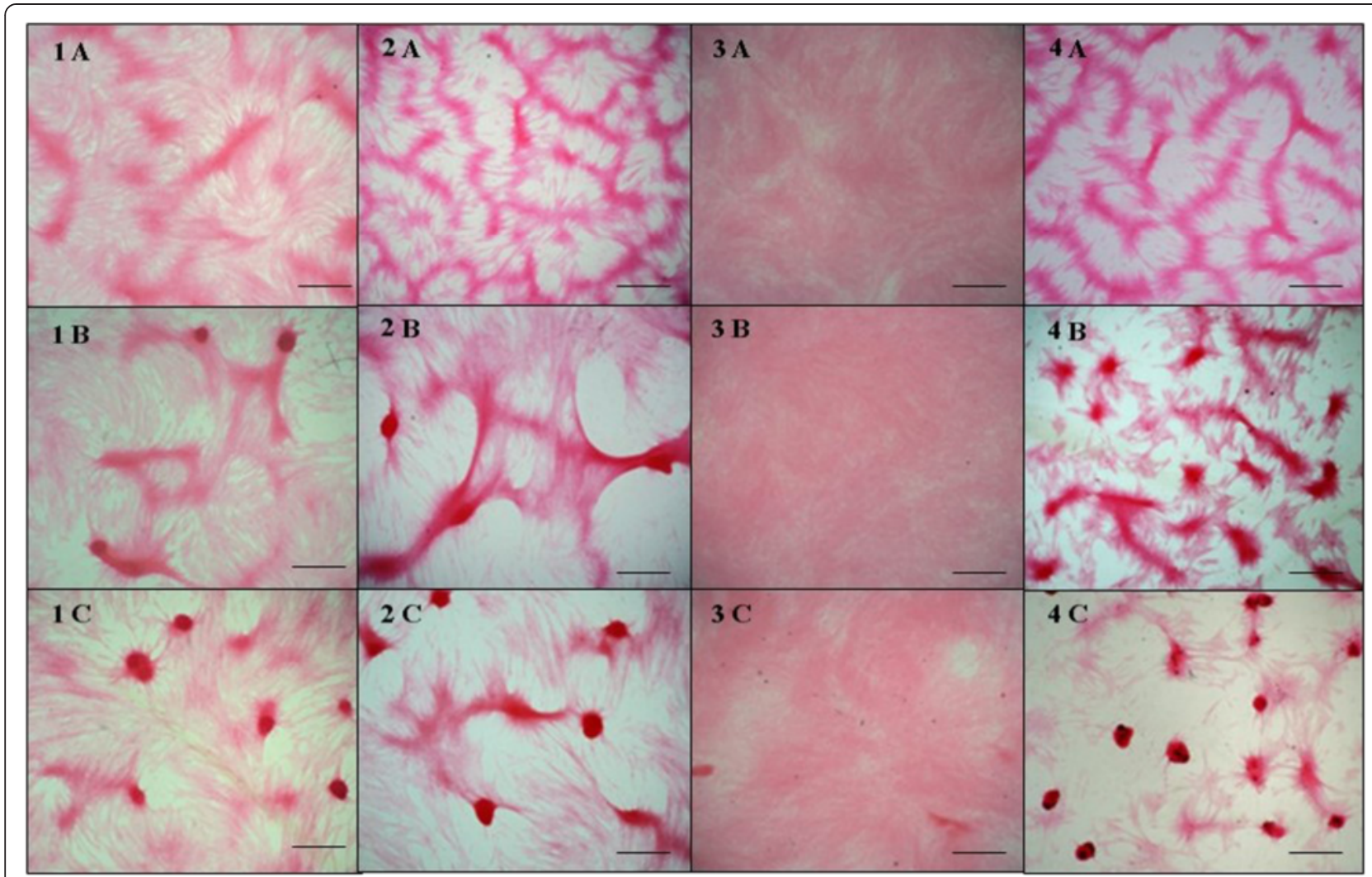

Fig. 2 Canine osteoblast culture maintained in basal medium (DMEM) (1), ionic product in basal medium (IP DMEM) (2), osteogenic medium (OST) (3) and ionic product in osteogenic medium (IP OST) (4) for 7 (a), 14 (b), and 21 (c) days. The mineralisation nodules dyed by the Von Kossa technique can be observed. The groups with IP, IP DMEM (2) and IP OST (4), exhibited larger mineralised area per field and greater maturation of the extracellular matrix than their respective controls, DMEM (1) and OST (3). Bar $=350 \mu \mathrm{m}$

maintained in DMEM at 7 and 21 days, and no difference was observed at 14 days (Fig. 6). The IP OST group exhibited greater ON expression than did the OST group at 7, 14, and 21 days of culture (Fig. 6). Higher ON expression was found in the OST group relative to the $D M E M$ group at 7,14 , and 21 days (Fig. 6). The cultures maintained in IP OST exhibited greater ON expression than those maintained in IP DMEM at 7, 14, and 21 days of culture (Fig. 6).
The osteoblast cultures maintained in IP DMEM displayed lower osteocalcin (OC) expression than those maintained in $D M E M$ at 7 days, and no difference was observed at 14 and 21 days (Fig. 7). The IP OST group displayed greater OC expression than the OST group at 14 and 21 days. At 7 days, the opposite was observed (Fig. 7), with greater OC expression observed in the OST group relative to the DMEM group, and no difference was observed at 14 and 21 days (Fig. 7). The cultures
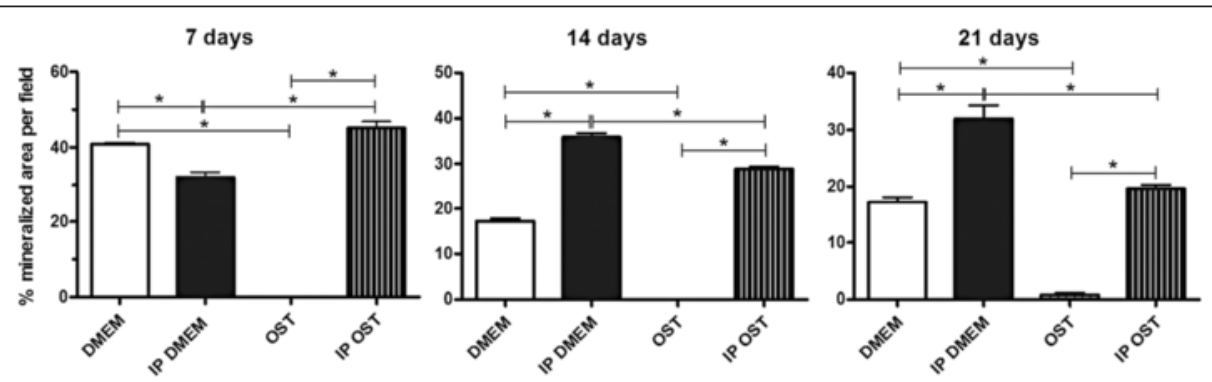

Fig. 3 Mean percentage and standard deviation of the mineralised area per field in canine osteoblast cultures cultivated in basal medium (DMEM), ionic product in basal medium (IP DMEM), osteogenic medium (OST) and ionic product in osteogenic medium (IP OST) for 7,14 and 21 days. ${ }^{*}(P<0.05)$ 


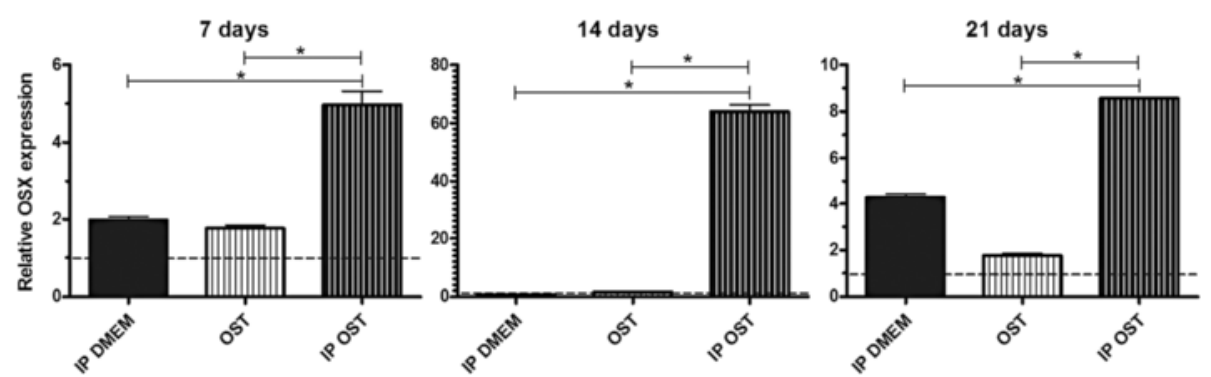

Fig. 4 Mean and standard deviation of gene transcription for osterix (OSX) by RT-PCR in canine osteoblast cultures maintained in basal medium (DMEM), ionic product in basal medium (IP DMEM), osteogenic medium (OST) and ionic product in osteogenic medium (IP OST) for 7, 14 and 21 days. The dotted line represents the expression of canine osteoblasts in basal medium (DMEM).* $(P<0.05)$

maintained in IP OST exhibited greater OC expression than those maintained in IP DMEM at 7, 14, and 21 days of culture (Fig. 7).

\section{Discussion}

The biological effect of biomaterials can be evaluated by their dissolution product [3] because the ions liberated during dissolution contribute for the biological effect [7]. The increased concentration of $\mathrm{Si}$ (more than $400 \%$ ) and $\mathrm{Ca}$ ions (more than $75 \%$ ) from the dissolution of BG60S was expected; however, it was significantly higher than the values reported in the literature with bioglass of different compositions $[8,9]$. This result indicates that the same type of biomaterial can produce different results according to the specific composition, which explains the various responses found in the literature.

The increase in AP activity in group IP DMEM relative to group $D M E M$ at 7 and 14 days suggests a stimulating effect of the IP on the secreting activity of the osteoblast. $\mathrm{AP}$ is an enzyme that occurs in the membrane of the osteoblast, and it directly participates in the synthesis and mineralisation of bone matrix [10]. This enzyme is commonly used as a marker of osteogenic differentiation [11] and a parameter for the evaluation of the bone activity, and high AP activity also indicates high osteoblastic activity [7].
The significant increase of the extracellular matrix area and greater mineralisation of the extracellular matrix observed in cultures that received the IP shows the stimulating effect that IPs of BG60S have on osteoblasts with regard to matrix synthesis and mineralisation. The synthesis and mineralisation of the extracellular matrix are considered the most reliable and representative parameters of in vitro osteoblastic activity [12]. The predominant increase of OSX, BSP and ON expression in the cultures that received the IP relative to those that did not suggests that the IP of BG60S stimulates the synthesis and mineralisation of the extracellular matrix by increasing the expression of these proteins. OSX is a specific transcription factor of osteogenic differentiation $[13,14]$ that acts on the transformation of preosteoblasts into mature osteoblasts [10, 15]. Furthermore, OSX acts on the synthesis and mineralisation of bone matrix via the intranuclear receptor of vitamin D and on the inhibition of osteoblastic proliferation via the inhibition of Wnt (Wingless-type MMTV integration site family) signalling $[13,14]$. BSP and ON are non-collagen proteins in bone matrix used as markers of osteogenic differentiation and osteoblastic activity [11, 16, 17]. These proteins are intimately related to the synthesis and mineralisation process of extracellular bone matrix [10]. Although the IP did not clearly increase OC
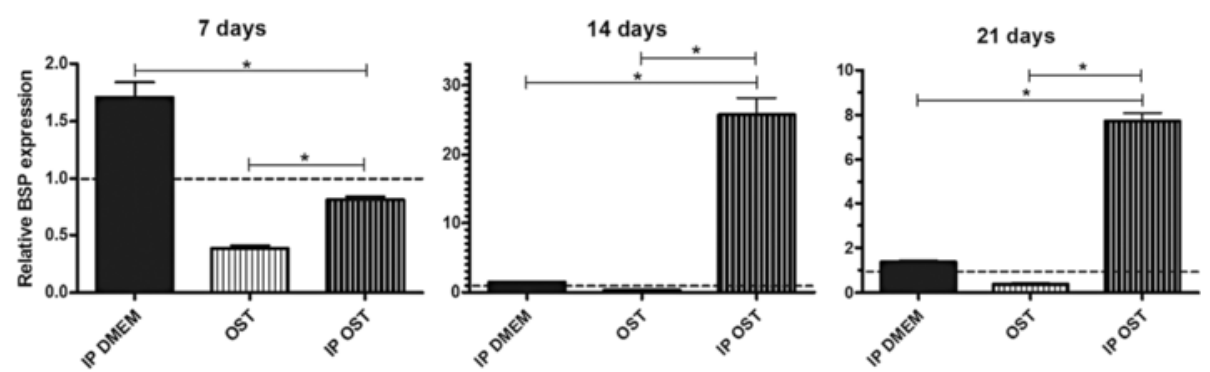

Fig. 5 Mean and standard deviation of gene transcription for bone sialoprotein (BSP) by RT-PCR in canine osteoblast cultures maintained in basal medium (DMEM), ionic product in basal medium (IP DMEM), osteogenic medium (OST) and ionic product in osteogenic medium (IP OST) for 7,14 and 21 days. The dotted line represents the expression of canine osteoblasts maintained in basal medium (DMEM). ${ }^{*}(P<0.05)$ 


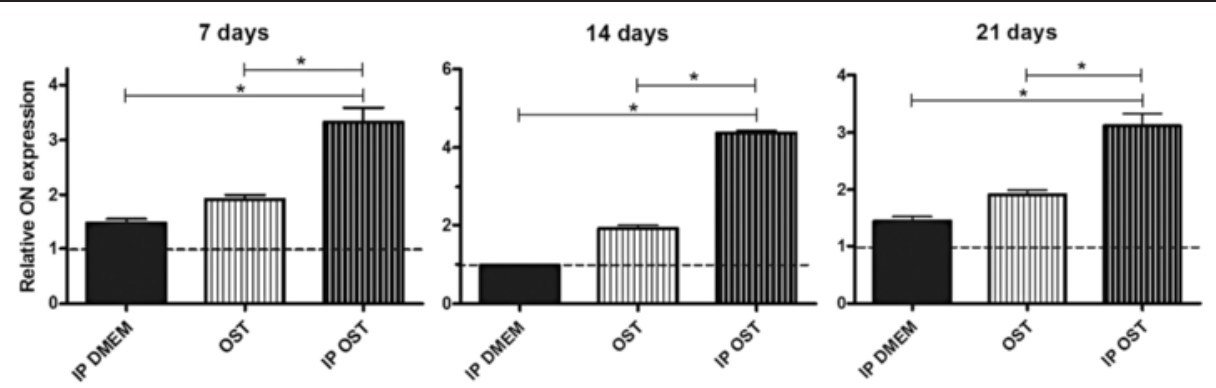

Fig. 6 Mean and standard deviation of gene transcription for osteonectin (ON) by RT-PCR in canine osteoblast cultures maintained in basal medium (DMEM), ionic product in basal medium (IP DMEM), osteogenic medium (OST) and ionic product in osteogenic medium (IP OST) for 7, 14 and 21 days. The dotted line represents the expression of canine osteoblasts in basal medium $(D M E M) . *(P<0.05)$

expression, the increase in its expression in the $I P$ OST group at 14 and 21 days suggests that the ions released by BG60S can also positively influence its expression. OC is a specific bone tissue glycoprotein expressed by osteoblasts and is considered the main non-collagen protein of bone matrix $[16,17]$. The evaluation of its expression can be used for monitoring bone metabolism [15].

The beneficial effects of the IP of BG60S on osteoblastic activity are most likely caused by the $\mathrm{Si}$ and $\mathrm{Ca}$ ions released during its dissolution process. Studies with rat osteoblast cultures have demonstrated that $\mathrm{Si}$ can increase cellular activity and proliferation [18] as well as the expression of runx2, collagen type 1 and ON [19]. Furthermore, Si can favour the mineralisation of extracellular matrix [18]. Ca is another ion released during BG60S dissolution, and it can increase the activity and proliferation of human mesenchymal stem cells $[4,5]$. Studies have indicated that extracellular Ca can increase osteopontin, OC, BSP and bone morphogenetic protein2 (BMP 2) expression in human mesenchymal stem cells [4]. Additionally, Ca favours the synthesis and mineralisation of extracellular matrix by human mesenchymal stem cells [5]. The previously mentioned studies have indicated that $\mathrm{Ca}$ favours in vitro osteogenesis; however, little is known of the mechanisms involved. The increase in extracellular $\mathrm{Ca}$ can increase the expression of osteopontin and BSP in mouse pre-osteoblasts, an effect mediated by L-type Ca channels and the $\mathrm{Ca} /$ calmodulindependent protein kinase 2 (CaM-CaMK2) signalling pathway [6].

With the limitations of the current study, there is only assessment of the $60 \mathrm{~S}$ bio-glass in the form of its ionic product. Although assessment of the product of dissolving the $60 \mathrm{~S}$ bio-glass may bring important information concerning its form of action, the biological response of a biomaterial may also be influenced by the size, form, microstructure, texture and topography of the implant surface. Thus, it is important to carry out complementary studies that may assess all these variables, allowing for a better understanding as to how each one of them influences its biological response.

\section{Conclusion}

The IP of BG60S alters the gene expression of canine osteoblasts, favouring the synthesis and mineralisation of extracellular matrix.

\section{Methods}

This study was performed according to the international norms for animal welfare and approved by the UFMG
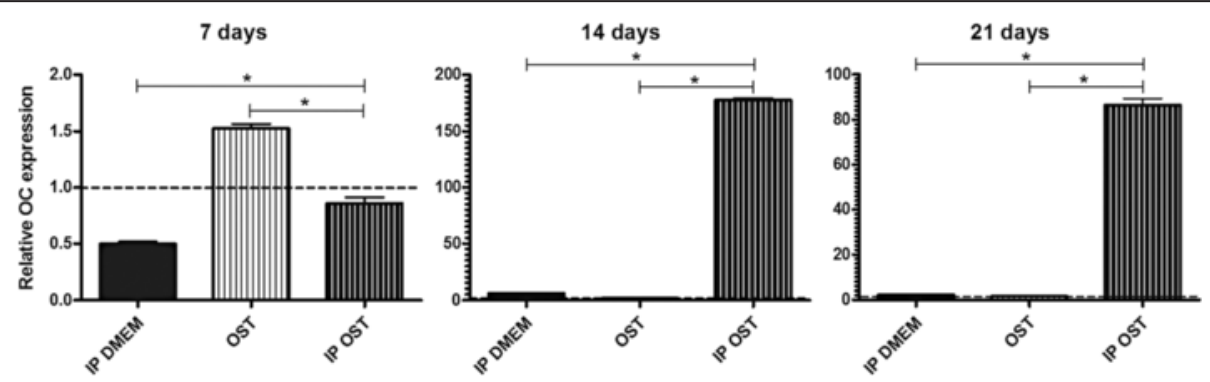

Fig. 7 Mean and standard deviation of gene transcription for osteocalcin (OC) by RT-PCR in canine osteoblast cultures maintained in basal medium (DMEM), ionic product in basal medium (IP DMEM), osteogenic medium (OST) and ionic product in osteogenic medium (IP OST) for 7,14 and 21 days. The dotted line represents the expression of canine osteoblasts maintained in basal medium (DMEM). ${ }^{*}(P<0.05)$ 
Animal Experimentation Ethics Committee (protocol n. 157/2009).

\section{Biomaterial and ionic product}

BG60S with a molar composition $4 \% \mathrm{P}_{2} \mathrm{O}_{5} 36 \% \mathrm{CaO}$ $60 \% \mathrm{SiO}_{2}$ was produced with $133.8 \mathrm{~mL}$ tetraethyl orthosilicate (TEOS), $13.6 \mathrm{~mL}$ triethyl phosphate (TEP), $97.9 \mathrm{~mL}$ deionised water, $16.3 \mathrm{~mL} 2 \mathrm{~N}$ nitric acid solution and $85.01 \mathrm{~g}$ Ca nitrate $\left[\mathrm{Ca}\left(\mathrm{NO}_{3}\right)_{2} 4 \mathrm{H}_{2} \mathrm{O}\right]$ in accordance with the protocol described by Coelho et al. [1]. The biomaterial was incubated at $60{ }^{\circ} \mathrm{C}$ for $72 \mathrm{~h}$ for gelation and maturation and then remained at $60{ }^{\circ} \mathrm{C}$ for $72 \mathrm{~h}$ for drying, which was followed by gradual temperature increase of $10{ }^{\circ} \mathrm{C}$ every $24 \mathrm{~h}$ until reaching $120{ }^{\circ} \mathrm{C}$. After drying, the sample was milled, and the grain size fraction smaller than $137 \mu \mathrm{m}$ was separated. The elimination of possible residues was performed by heating in a muffle furnace at $700{ }^{\circ} \mathrm{C}$ for $6 \mathrm{~h}$ and applying a heating and cooling rate of $1{ }^{\circ} \mathrm{C}$ per minute. To obtain the IP, $6 \mathrm{~g}$ biomaterial was added to $1 \mathrm{~L}$ lowglucose Dulbecco's modified Eagle's medium (Gibco, CA, USA) containing gentamicin $(60 \mu \mathrm{g} / \mathrm{L})$, penicillin $(100 \mathrm{U} / \mathrm{mL})$, streptomycin $(100 \mu \mathrm{g} / \mathrm{mL})$ and amphotericin $(25 \mu \mathrm{g} / \mathrm{mL})$ (PSA, Sigma-Aldrich, USA). The mixture was homogenised and incubated for $12 \mathrm{~h}$ at $6{ }^{\circ} \mathrm{C}$. After incubation, the suspension was filtered using a $22 \mu \mathrm{m}$ membrane, and the $\mathrm{pH}$ was adjusted to 7.2 , which resulted in the IP of BG60S.

\section{Concentrations of $\mathrm{Si}$ and $\mathrm{Ca}$ ions in the cell culture media}

Prior to the use of the culture media with canine osteoblasts, the concentration of $\mathrm{Si}$ and $\mathrm{Ca}$ ions in the media was measured. The atomic absorption spectrometry technique (GBC-Avanta) was used according to the standard addition method to determine the ion concentration.

\section{Preparation and cultivation of osteoblasts and formation of the experimental groups}

A canine osteoblast culture $(\mathrm{CnOb}$ - canine osteoblasts, Cell Application, CA, USA) was used to evaluate the effect of the IP of BG60S. The culture was defrosted, and then the pellet was plated and cultivated in T75 flaks with low-glucose DMEM (Gibco, CA, USA) containing gentamicin $(60 \mu \mathrm{g} / \mathrm{L})$, penicillin $(100 \mathrm{U} / \mathrm{mL})$, streptomycin $(100 \mu \mathrm{g} / \mathrm{mL})$ and amphotericin $(25 \mu \mathrm{g} / \mathrm{mL})$ (PSA, Sigma-Aldrich, USA) and enriched with $10 \%$ foetal bovine serum (FBS - Soralis, Brazil) [basal medium]. The flasks were maintained in an incubator at $37{ }^{\circ} \mathrm{C}$ and $5 \%$ $\mathrm{CO}_{2}$. The culture medium was changed twice per week, and when 80-90\% confluence was achieved, the cells were subcultured. On the third subculture after obtaining 80-90\% confluence, the osteoblasts were used for the evaluation of the $I P$, and the following groups were formed: DMEM, IP DMEM [IP enriched with $10 \%$ FBS], OST [basal medium enriched with ascorbic acid $(50 \mu \mathrm{g} / \mathrm{mL}), ß$-glycerophosphate $(10 \mathrm{mM})$ (Sigma-Aldrich, USA), dexamethasone $(0.1 \mu \mathrm{M})$ (Aché, Brazil) and $10 \%$ FBS] and IP OST [IP enriched with ascorbic acid $(50 \mu \mathrm{g} / \mathrm{mL})$, ß-glycerophosphate $(10 \mathrm{mM})$, dexamethasone $(0.1 \mu \mathrm{M})$ and $10 \% \mathrm{FBS}]$.

The osteoblasts were cultivated in quadruplicate at $37{ }^{\circ} \mathrm{C}$ and $5 \% \mathrm{CO}_{2}$ for 7,14 and 21 days with DMEM, IP DMEM, OST or IP OST. Subsequently, the AP activity, mineralised area per field and the relative expression of OSX, BSP, ON and OC were evaluated in each group by reverse transcriptase (RT)-PCR.

\section{Alkaline phosphatase activity}

For the evaluation of AP activity, the osteoblasts of each group were cultivated separately in 24-well plates. At the end of each period, the cultures were washed with phosphate buffered saline (PBS - 0.15 molar). To each well, $200 \mu \mathrm{L}$ of 5-Bromo-4-Chloro-3-Indolyl phosphate/nitroblue tetrazolium salt (BCIT/NBT) solution (Zymed Laboratories, USA) was added. The samples were incubated for $2 \mathrm{~h}$ in an oven at $37{ }^{\circ} \mathrm{C}$ and $5 \% \mathrm{CO}_{2}$ and observed under an optical microscope before the addition of $200 \mu \mathrm{L}$ of sodium dodecyl sulphate (SDS)-10 \% $\mathrm{HCl}$. These samples were placed in an oven overnight at $37^{\circ} \mathrm{C}$ and $5 \% \mathrm{CO}_{2}$, and then $100 \mu \mathrm{L}$ from each well was transferred to 96-well plates and read by a spectrophotometer at $595 \mathrm{~nm}$ [11].

\section{Evaluation of mineralised matrix synthesis}

To evaluate the percentage of mineralised matrix per field, the osteoblasts of each group were cultivated separately in 6-well plates with cover slips (Sarstedt, USA). After each evaluation period, the osteoblasts were fixed with $70 \%$ ethanol for $24 \mathrm{~h}$ and dyed using the Von Kossa method. The percentage of mineralised matrix per field was determined with an ocular micrometer containing a 121-point grid, with 25 fields and a $4 \times$ objective [11].

\section{Quantification of gene transcription for OSX, BSP, ON and $O C$}

For the relative quantification of gene transcription for OSX, BSP, ON and OC by RT-PCR, the osteoblasts of each group were cultivated in quadruplicate in T25 flasks. At the end of each evaluation period, the total RNA was extracted from the cultures of each bottle with Trizol (Invitrogen, USA) following the manufacturer's protocol. The RNA was solubilised in RNase-free diethylpyrocarbonate (DEPC) water (Invitrogen, USA) and immediately stored at $-80{ }^{\circ} \mathrm{C}$. The RNA concentration was determined by an absorbance reading at 260/ $280 \mathrm{~nm}$ by spectrophotometry. Reverse transcription reactions were performed using Kit SuperScript ${ }^{\text {tix }}$ III 
Table 1 Genes and nucleotide sequence of primers used for RT-PCR

\begin{tabular}{|c|c|c|c|}
\hline $\begin{array}{l}\text { Gene } \\
\text { Reference or Accession No. }\end{array}$ & $\begin{array}{l}\text { Primer } \\
\text { (5' to } 3^{\prime} \text { nucleotide sequences) }\end{array}$ & $\begin{array}{l}\text { Annealing } \\
\text { temperature }\left({ }^{\circ} \mathrm{C}\right)\end{array}$ & $\begin{array}{l}\text { Product size } \\
\text { (base pairs) }\end{array}$ \\
\hline OSX & F- ACGACACTGGGCAAAGCAG & 60 & 285 \\
\hline Neupane et al. [16] & R- CATGTCCAGGGAGGTGTAGAC & & \\
\hline BSP & F- TTGCTCAGCATITTGGGAAT & 60 & 295 \\
\hline Vieira et al. [17] & R- AACGTGGCCGATACTTAAAGAC & & \\
\hline ON & F- GCCTTGGCAGCCCCTCAACA & 60 & 108 \\
\hline (XM_849889.1) & R- CACCTGCACGGGGTTGGCTC & & \\
\hline OC & F- GAGGGCAGCGAGGTGGTGAG & 62 & 134 \\
\hline Neupane et al. [16] & R- TCAGCCAGCTCGTCACAGTTGG & & \\
\hline GAPDH & F- CCATCTTCCAGGAGCGAGGAT & 60 & 97 \\
\hline Vieira et al. [17] & R- TTCTCCATGGTGGTGAAGAC & & \\
\hline
\end{tabular}

Platinum $^{\ominus}$ Two-Step (Invitrogen, USA). Total RNA $(1 \mu \mathrm{g})$ was used for cDNA synthesis, with a final volume of $20 \mu \mathrm{L}$. The PCR reactions were performed in realtime using $2 \mu \mathrm{g}$ of cDNA, $5 \mathrm{pM}$ of each primer and $12.5 \mu \mathrm{L}$ of the reagent SYBR Green at a final volume of $25 \mu \mathrm{L}$ reaction per well, in a 7500 Real-Time PCR System (Applied Biosystems, USA). The parameters used for amplification were $50{ }^{\circ} \mathrm{C}$ for $120 \mathrm{~s}, 95{ }^{\circ} \mathrm{C}$ for $150 \mathrm{~s}$ and 45 cycles, $95{ }^{\circ} \mathrm{C}$ for $15 \mathrm{~s}$ and $60{ }^{\circ} \mathrm{C}$ for $30 \mathrm{~s}$. The primers were researched in the literature or designed based on the sequence of Canis familiaris mRNA (Table 1). The gene expression was calculated with the method $2^{-\Delta \Delta C T}$, and the results obtained for each group were quantitatively compared after the normalisation based on the expression of Canis familiaris glyceraldehyde 3-phosphate dehydrogenase (GAPDH). The expression levels obtained in osteoblastic cultures cultivated in basal medium were used as expression standards to calculate the relative expression of each transcription.

\section{Statistical analysis}

An analysis of variance (ANOVA) was performed, and the mean and standard deviation were determined for each variable. The means were compared by Student's $t$-test using the program Graphpad Instat 3 (GraphPad Software Inc., USA). Differences were considered significant at $P<0.05$.

\footnotetext{
Abbreviations

AP: Alkaline phosphatase; ANOVA: Analysis of variance; BCIT: 5-Bromo-4Chloro-3-Indolyl phosphate; BMP-2: Bone morphogenetic protein-2; BSP: Bone sialoprotein; Ca: Calcium; cDNA: Complementary DNA; CETEA: Animal experimentation ethics committee (Comitê de Ética em Experimentação Animal); DEPC: Diethylpyrocarbonate; DMEM: Dulbecco's modified Eagle's medium (basal medium); FBS: Foetal bovine serum; GAPDH: Glyceraldehyde-3-phosphate dehydrogenase; mRNA: RNA messenger; NBT: Nitroblue tetrazolium salt; NCT-TCA: Centre for Stem Cells and Animal Cell Therapy (Núcleo de Células Tronco e Terapia Celular Animal); OC: Osteocalcin; OSX: Osterix; IP: Ionic product; IP DMEM: Ionic product in basal medium; IP OST: Ionic product in osteogenic medium; PSA: Penicillin, streptomycin and amphotericin; qRT-PCR: Quantitative reverse
}

transcription polymerase chain reaction; RNA: Ribonucleic acid; RNase: Ribonuclease enzyme; RUNX-2: Runt-related transcription factor 2; SDS: Sodium dodecyl sulphate; Si: Silicon; TEOS: Tetraethylorthosilicate; TEP: Triethylphosphate; UFMG: Federal University of Minas Gerais (Universidade Federal de Minas Gerais); UNIUBE: University of Uberaba (Universidade de Uberaba); Wnt: Wingless-type MMTV integration site family.

\section{Competing interests}

The present study does not have any competing interests.

\section{Authors' contributions}

EGLA proposed the concept of the study, performed the laboratory tests and statistical analysis and participated in the drafting of the manuscript. IRR participated in the laboratory tests and statistical analysis and in the drafting of the manuscript. RS, MMP, NMO, HPO and AMG participated in the analysis and interpretation of data for drafting of the manuscript. CMFR coordinated the study, participated in the design and harmonised the drafting of the manuscript. All of the authors read and approved the final manuscript.

\section{Acknowledgements}

The authors would like to thank the Foundation for Research Support of the State of Minas Gerais (Fundação de Amparo à Pesquisa do Estado de Minas Gerais - FAPEMIG) for funding the study, National Council of Scientific and Technological Research (Conselho Nacional de Desenvolvimento Científico e Tecnológico - CNPq) for the doctoral grant, and the Veterinary School, Laboratory of Molecular Biology of the Department of Immunology and Biochemistry of the Institute of Biological Sciences, Laboratory of Biomaterials of the Department of Metallurgical Engineering and Materials and Dean of the Research Office of the Federal University of Minas Gerais (Pro-Reitoria de Pesquisa da Universidade Federal de Minas Gerais) for the support required to conduct this study.

\section{Author details}

${ }^{1}$ Veterinary Medicine Program at the University of Uberaba (Universidade de Uberaba - UNIUBE), Uberaba, Brazil. ${ }^{2}$ Center for Stem Cells and Animal Cell Therapy (Núcleo de Células Tronco e Terapia Celular Animal - NCT-TCA), Department of Medicine and Surgery, Veterinary School of the Federal University of Minas Gerais (Universidade Federal de Minas Gerais - UFMG), Belo Horizonte, Brazil. 'aboratory of Biomaterials of the Department of Metallurgic and Materials Engineering at UFMG, Belo Horizonte, Brazil. ${ }^{4}$ Department of Biochemistry and Immunology of the Institute of Biological Sciences at UFMG, Belo Horizonte, Brazil.

Received: 25 November 2014 Accepted: 21 September 2015 Published online: 30 September 2015

\section{References}

1. Coelho MB, Pereira MM. Sol-gel synthesis of bioactive glass scaffolds for tissue engineering: effect of surfactant type and concentration. J Biomed Mater Res B Appl Biomater. 2005;75:451-6. 
2. Dutra CE, Pereira MM, Serakides R, Rezende CMF. In vivo evaluation of bioactive glass foams associated with platelet-rich plasma in bone defects. J Tissue Eng Regen Me. 2008;4:221-7.

3. Valério P, Pereira MM, Goes AM, Leite MF. The effect of ionic products from bioactive glass dissolution on osteoblast proliferation and collagen production. Biomaterials. 2004;25:2941-8.

4. Barradas AMC, Fernandes HAM, Groen N, Chai YC, Schrooten J, van de Peppel J, et al. A calcium-induced signalling cascade leading to osteogenic differentiation of human bone marrow-derived mesenchymal stromal cells. Biomaterials. 2012;33:3205-15.

5. Mccullen SD, Zhan J, Onorato ML, Bemacki SH, Loboa EG. Effect of varied ionic calcium on human adipose-derived stem cell mineralization. Tissue Eng Part A. 2010:16:1971-81.

6. Jung GY, Park YJ. Effects of HA-released calcium ions on osteoblast differentiation. J Mater Sci Mater Med. 2010;2:1649-54.

7. Li HW, Sun JY. Effects of dicalcium silicate coating ionic dissolution products on human mesenchymal stem-cell proliferation and osteogenic differentiation. J Int Med Res. 2011;39:112-28.

8. Tsigkou O, Jones JR, Polak JM, Stevens MM. Differentiation of fetal osteoblasts and formation of mineralized bone nodules by $45 \mathrm{~S} 5$ Bioglass conditioned medium in the absence of osteogenic supplements. Biomaterials. 2009:30:3542-50.

9. Alno N, Jegoux F, Pellen-Mussi P, Tricot-Doleux S, Oudadesse H, Cathelineau $\mathrm{G}$, et al. Development of a three-dimensional model for rapid evaluation of bone substitutes in vitro: Effect of the 4555 bioglass. J Biomed Mater Res A. 2010;95:137-45.

10. Franceschi RT, Ge C, Xiao G, Roca H, Jiang D. Transcriptional regulation of osteoblasts. Cells Tissues Organs. 2009:189:144-52.

11. Alves EGL, Serakides R, Boeloni JN, Rosado IR, Ocarino NM, Oliveira HP, et al. Comparison of the osteogenic potential of mesenchymal stem cells from the bone marrow and adipose tissue of young dogs. BMC Vet Res 2014 2014;10:190.

12. Bruedigan C, Driel MV, Koedam M, Peppel JV, van der Eerden BC, Eijken M, et al. Basic techniques in human mesenchymal stem cell cultures: differentiation into osteogenic and adipogenic lineages, genetic perturbations, and phenotypic analyses. Curr Protoc Stem Cell Biol. 2011;17:1-19.

13. Long F. Building strong bones: molecular regulation of the osteoblast lineage. Nat Rev Mol Cell Biol. 2012;13:27-38.

14. Zhang C. Molecular mechanisms of osteoblast-specific transcription factor osterix effect on bone formation. Beijing Da Xue Xue Bao. 2012:44:659-65.

15. Nishimura R, Hata K, Matsubara T, Wakabayashi M, Yoneda T. Regulation of bone and cartilage development by the network between BMP signalling and transcription factors. J Biochem. 2012:151:247-54.

16. Neupane M, Chang C, Kiupel M, Yuzbasiyan-Gurkan V. Isolation and characterization of canine adipose-derived mesenquimal stem cells. Tissue Eng A. 2008;14:1007-15.

17. Vieira NM, Brandalise V, Zucconi E, Secco M, Strauss BE, Zatz M. Isolation, characterization, and differentiation potential of canine adipose-derived stem cells. Cell Transplant. 2010;19:279-89.

18. Shie MY, Ding SJ, Chang HC. The role of silicon in osteoblast-like cell proliferation and apoptosis. Acta Biomater. 2011;7:2604-14.

19. Varanasi VG, Leong KK, Dominia LM, Jue SM, Loomer PM, Marshall GW. Si and Ca individually and combinatorially target enhanced MC3T3-E1 subclone 4 early osteogenic marker expression. J Oral Implantol. 2012;38:325-36.

\section{Submit your next manuscript to BioMed Central and take full advantage of:}

- Convenient online submission

- Thorough peer review

- No space constraints or color figure charges

- Immediate publication on acceptance

- Inclusion in PubMed, CAS, Scopus and Google Scholar

- Research which is freely available for redistribution

Submit your manuscript at www.biomedcentral.com/submit 